OPEN ACCESS

Check for updates

\title{
Acute urinary retention and risk of cancer: population based Danish cohort study
}

\author{
Maria Bisgaard Bengtsen, ${ }^{1}$ Dóra Körmendiné Farkas, ${ }^{1}$ Michael Borre, ${ }^{2}$ Henrik Toft Sørensen, ${ }^{1}$ \\ Mette Nørgaard ${ }^{1}$
}

${ }^{1}$ Department of Clinical

Epidemiology, Aarhus University Hospital and Department of Clinical Medicine, Aarhus University, 8200 Aarhus N, Denmark

${ }^{2}$ Department of Urology, Aarhus University Hospital, Aarhus,

Denmark

Correspondence to:

M B Bengtsen

mariabb@clin.au.dk

(or @dceaarhus on Twitter

ORCID 0000-0002-4241-7213)

Additional material is published online only. To view please visit the journal online.

Cite this as: $B M J$ 2021;375:n2305 http://dx.doi.org/10.1136/bmj.n2305

Accepted: 20 September 2021

\section{ABSTRACT}

OBJECTIVE

To examine the risk of urogenital, colorectal, and neurological cancers after a first diagnosis of acute urinary retention.

\section{DESIGN}

Nationwide population based cohort study.

SETTING

All hospitals in Denmark.

\section{PARTICIPANTS}

75983 patients aged 50 years or older with a first hospital admission for acute urinary retention during 1995-2017.

\section{MAIN OUTCOME MEASURES}

Absolute risk of urogenital, colorectal, and neurological cancer and excess risk of these cancers among patients with acute urinary retention compared with the general population.

RESULTS

The absolute risk of prostate cancer after a first diagnosis of acute urinary retention was $5.1 \%$ $(n=3198)$ at three months, 6.7\% $(n=4233)$ at one year, and $8.5 \%(n=5217)$ at five years. Within three months of follow-up, 218 excess cases of prostate cancer per 1000 person years were detected. An additional 21 excess cases per 1000 person years were detected during three to less than 12 months of follow-up, but beyond 12 months the excess risk was negligible. Within three months of follow-up the excess risk for urinary tract cancer was 56 per 1000 person years, for genital cancer in women was 24 per 1000 person years, for colorectal cancer was 12 per 1000 person years, and for neurological cancer was 2 per 1000 person years. For most of the studied cancers, the excess risk was confined to within three months of follow-up, but the risk of prostate and urinary tract cancer remained increased during three to less than 12 months of follow-up. In women, an

\section{WHAT IS ALREADY KNOWN ON THIS TOPIC}

Acute urinary retention might be a clinical marker of occult cancer

Existing evidence is sparse, of older age, and limited to data from only one institution

\section{WHAT THIS STUDY ADDS}

Acute urinary retention was found to be a clinical marker of prostate and other cancers

For most cancers, the excess cancer risk was confined to the first three months after a diagnosis of acute urinary retention

Occult cancer should possibly be considered in patients who present with acute urinary retention and no obvious underlying cause

excess risk of invasive bladder cancer persisted for several years.

\section{CONCLUSIONS}

Acute urinary retention might be a clinical marker for occult urogenital, colorectal, and neurological cancers. Occult cancer should possibly be considered in patients aged 50 years or older presenting with acute urinary retention and no obvious underlying cause.

\section{Introduction}

Acute urinary retention is characterised by a sudden, painful inability to void that requires immediate decompression of the bladder. ${ }^{12}$ The incidence of this condition in men is 2.2 to 8.8 per 1000 men per year, and it increases substantially with age. ${ }^{3}$ An estimated $10 \%$ of men in their 70 s and $30 \%$ in their 80 s will develop acute urinary retention. ${ }^{4}$ The incidence in women is not well examined, but a female to male ratio of $1: 13$ has been estimated. ${ }^{5}$

Common mechanisms leading to acute urinary retention can be categorised as obstructive, infectious, inflammatory, drug related, neurological, or other. ${ }^{6}$ The most common cause among men is obstruction secondary to benign prostatic hyperplasia ${ }^{6}$ whereas detrusor muscle failure is the most common cause among women. ${ }^{5}$

Although most underlying causes are benign, acute urinary retention is also a presenting sign of prostate cancer, and some research indicates that it might also be the presenting sign of other urogenital, gastrointestinal, and neurological cancers. ${ }^{7}$ These cancers can lead to acute urinary retention through intrinsic obstruction (eg, prostate cancer, bladder cancer), extrinsic obstruction (eg, a pelvic or abdominal mass compressing the bladder neck), ${ }^{7}$ or interference of the contractile function of the bladder or urethra. ${ }^{8}$ Although urogenital, colorectal, and neurological cancers have been suggested to cause acute urinary retention, ${ }^{2-8}$ evidence is limited. We are unaware of studies that have estimated the absolute and relative risk of these cancers after a first diagnosis of acute urinary retention, except for prostate cancer. ${ }^{9}$

We examined the risk of urogenital, colorectal, and neurological cancers among patients with a first hospital admission for acute urinary retention compared with the general population.

\section{Methods}

Setting, data sources, and study population We conducted a nationwide cohort study in Denmark, which had 5.8 million residents in $2018 .^{10}$ In the Danish national health service all residents have free 
access to general practitioners and hospitals and are partially reimbursed for prescribed drugs. ${ }^{11}$ At birth or immigration, Danish residents are assigned a unique social security number, which allows accurate linkage between Danish medical databases and public registries. $^{12}$

The Danish National Patient Registry contains data on all admissions to Danish hospitals since 1977 as well as data on visits to emergency departments and outpatient clinics since $1995 .^{13}$ Outpatient visits include visits to hospital based (ambulatory) specialty clinics. The registry does not capture visits to private practice specialists or general practitioners. Each hospital admission or outpatient visit is linked to one primary diagnosis (the main reason for the hospital contact) and, when relevant, to several secondary diagnoses. Diagnoses in the Danish National Patient Registry are classified according to ICD-8 (international classification of diseases, eighth revision) until the end of 1993 , and then to the ICD-10 (10th revision). ${ }^{13}$ See supplementary table 1 for the codes used in our study.

The Danish National Patient Registry was used to identify a cohort of patients with a first primary or secondary inpatient, outpatient, or emergency department diagnosis of acute urinary retention from 1 January 1995 to 31 December 2017. To ensure that our cohort was restricted to patients with a first hospital admission, we excluded those with a diagnosis of acute urinary retention from 1 January 1977 to 31 December 1994. We also restricted the cohort to patients aged 50 years or older, as the incidence of the cancers in this study is low in younger people. As our primary outcome was a first cancer diagnosis, we excluded patients with a diagnosis of any cancer (except non-melanoma skin cancer) before the diagnosis of acute urinary retention. We also excluded patients who underwent surgery within seven days before the diagnosis of acute urinary retention, as we did not want to include post-surgical episodes. We used this seven day window to exclude those with surgery as the most obvious underlying cause.

\section{Cancer}

Information on selected incident cancers was obtained from the Danish Cancer Registry, which was established in 1943. This registry contains data on all cancers diagnosed in Denmark, classified according to ICD-10 and ICD Oncology codes (ICD-0-1-3) for topography and morphology. ${ }^{14}$

We categorised cancers into those of the urinary tract, genitals, colorectum, and nervous system. The sites for the urogenital cancers were prostate, bladder (invasive cancer, non-invasive cancer), kidney, renal pelvis, and genitals in women. No formal population screening for prostate cancer existed during our study period.

\section{Covariates and confounders}

From the Danish National Patient Registry, we collected data on previous diagnoses known to increase the risk of acute urinary retention, ${ }^{2}{ }^{6}$ including urogenital diseases, neurological diseases, and diabetes. We included chronic urogenital and neurological diseases (eg, benign prostatic hyperplasia, multiple sclerosis, diabetes mellitus) in the analysis if they were ever recorded in the national registry. Acute diseases (infections and inflammatory diseases) were included only if they were diagnosed within 14 days before the diagnosis of acute urinary retention.

We defined the presence of a comorbidity as a record in the Danish National Patient Registry of at least one of the 19 chronic diseases included in the Charlson comorbidity index ${ }^{15}$ at any time before the diagnosis of acute urinary retention. We classified the acute urinary retention as primary if the diagnosis was primary or if the primary diagnosis was benign prostatic hyperplasia combined with a secondary diagnosis of acute urinary retention. ${ }^{1617}$ All other cases of acute urinary retention were classified as secondary. We defined concomitant haematuria as a diagnosis of haematuria registered at the same date or within a month before the diagnosis of acute urinary retention.

\section{Statistical analysis}

Each patient was followed from the date of the first diagnosis of acute urinary retention (hospital admission, outpatient, or emergency department contact date) until the date of a first cancer diagnosis (any type of cancer except non-melanoma skin cancer), death, emigration, or 31 December 2018, whichever came first.

We computed distributions and frequencies of baseline characteristics at the time acute urinary retention was diagnosed. These characteristics included sex, age category (50-64, 65-79, and $\geq 80$ years), type of urinary retention (primary or secondary), type of hospital contact (inpatient, outpatient clinic, or emergency department), presence of conditions related to acute urinary retention (urogenital disease, neurological disease, diabetes), and Charlson comorbidity index score $(0,1-2$, or $\geq 3)$. We also calculated median (interquartile range) followup time.

The absolute risk of cancer after three months, one year, and five years of follow-up was calculated, with death treated as a competing risk. ${ }^{18}$ We examined the risk of cancer for all patients as well as for men and women separately. The risk of genital cancer was assessed in men (including prostate cancer) and women separately.

The excess risk of cancer was computed as the difference between the observed and expected number of cancers divided by the total follow-up period. By applying cancer rates for the general Danish population, we estimated the expected number of cancers in our cohort of patients with acute urinary retention in each period of follow-up. We used data from the Danish Cancer Registry ${ }^{14}$ combined with information on the age and sex distribution of the Danish population ${ }^{10}$ to calculate the general population cancer rates stratified by sex, age (one year groups), and calendar year (one year groups) and 
multiplied these rates with the age, sex, and calendar year specific follow-up time accumulated in the cohort with acute urinary retention in the given period of follow-up. This yielded stratum specific numbers of the cancers, which we then summed to obtain the total number. Indirect standardised incidence ratios were used as a measure of relative risk, with the observed number of cancers in the acute urinary retention cohort divided by the expected number of cancers. The 95\% confidence intervals were calculated assuming a Poisson distribution. We classified the follow-up period as 0 to less than three months, three months to less than 12 months, and 1-5 years.

To investigate whether concomitant haematuria could potentially explain the association between acute urinary retention and urinary tract cancers, we performed a subanalysis excluding patients with a diagnosis of concomitant haematuria.

The statistical analyses were conducted using the SAS statistical software package, v. 9.4 (SAS Institute, Cary, NC).

\section{Patient and public involvement}

As this was a register based study, we did not involve patients or members of the public in the study design, interpretation of results, or development of the dissemination strategy. Although no patients or members of the public were directly involved owing to the methodological design of our study, we did ask a member of the public to read our manuscript before submission.

\section{Results}

\section{Study cohort}

Overall, 75983 patients aged 50 years or older with a first hospital admission for acute urinary retention during 1995-2017 were identified (table 1). Most were men $(82.6 \%, n=62753)$. Median follow-up was 3.3 years (interquartile range 1.1-7.0 years) and 27410 (36.1\%) of the patients had at least five years of followup. Median age was 76 (interquartile range 68-83) years.

At the time of their first diagnosis of acute urinary retention, $36483(48.0 \%)$ of all patients had a previous urogenital diagnosis, 20774 (27.3\%) had a previous neurological diagnosis, and 9996 (13.2\%) had diabetes.

\section{Prostate cancer}

The absolute risk of prostate cancer was 5.1\% (95\% confidence interval $4.9 \%$ to $5.3 \%$ ) at three months, $6.7 \%(6.6 \%$ to $6.9 \%)$ at one year, and $8.5 \%(8.3 \%$ to $8.7 \%$ ) at five years after a diagnosis of incident acute urinary retention (table 2 ). Within the first three months of follow-up, the observed number of prostate cancers was 3198 versus 93 expected, corresponding to 218 (95\% confidence interval 214 to 221) excess cancers per 1000 person years (standardised incidence ratio 34.5, 95\% confidence interval 33.3 to 35.7 ; table 3 ). Of these, $32 \%$ were localised, $24 \%$ had spread locally or metastasised, and $45 \%$ had missing information on stage. During three to less than 12 months of followup, an additional 1035 cases of prostate cancer were observed versus 244 expected, corresponding to 21 (95\% confidence interval 20 to 23) excess cancers per 1000 person years (standardised incidence ratio 4.2, $95 \%$ confidence interval 4.0 to 4.5 ). Beyond one year of follow-up, the risk of prostate cancer in patients with a diagnosis of acute urinary retention did not differ substantially from the risk in the general population (standardised incidence ratio 1.1, 95\% confidence interval 1.0 to 1.2). Of prostate cancers occurring in the latest period of follow-up, 31\% were localised, $27 \%$ had spread locally or metastasised, and $42 \%$ had missing information on stage.

The risk of prostate cancer during the first three months of follow-up decreased slightly over calendar time, from 5.7\% (95\% confidence interval 5.2\% to $6.3 \%$ ) in $1995-98$ to $4.6 \%$ (4.2\% to $4.9 \%$ ) in $2014-17$, corresponding to 249 and 194 excess cancers per 1000 person years, respectively (table 2 and table 3 ).

The absolute and relative risks of prostate cancer were particularly high among men with no previous conditions associated with acute urinary retention (eg, diabetes, urogenital disease, neurological disease) and no previous comorbidity (Charlson comorbidity index score 0 , table 2 and table 3 ).

\section{Urinary tract cancers}

The absolute risk of urinary tract cancer was $1.3 \%$ (95\% confidence interval $1.3 \%$ to $1.4 \%$ ) at three months, $1.8 \%(1.7 \%$ to $1.9 \%)$ at one year, and $2.5 \%$ $(2.4 \%$ to $2.7 \%)$ at five years after a first diagnosis of acute urinary retention (table 4).

Within the first three months of follow-up, the observed number of urinary tract cancers was 1025 versus 49 expected, corresponding to 56 (95\% confidence interval 54 to 58) excess cancers per 1000 person years (standardised incidence ratio 21.1, 95\% confidence interval 19.9 to 22.5 , table 5 ). The majority $(n=911,89 \%)$ were detected in men, and most were bladder cancers $(n=847,83 \%)$. Within three months after a first diagnosis of acute urinary retention in men, the observed number of invasive bladder cancers was 372 versus 19 expected and the observed number of non-invasive bladder cancers was 383 versus 18 expected, corresponding to 25 (95\% confidence interval 23 to 26) and 26 (24 to 27) excess cancers per 1000 person years, respectively. Within three months after a first diagnosis of acute urinary retention in women, the observed number of invasive bladder cancers was 62 versus 1 expected and the observed number of non-invasive bladder cancers was 30 versus 1 expected, corresponding to 20 (95\% confidence interval 17 to 22) and 9 (8 to 11) excess cancers per 1000 person years, respectively.

During three to less than 12 months of follow-up, the observed number of urinary tract cancers was 354 versus 127 expected, corresponding to 5 (95\% confidence interval 4 to 6 ) excess urinary tract cancers per 1000 person years (standardised incidence ratio 2.8, 95\% confidence interval 2.5 to 3.1). During one 


\begin{tabular}{|c|c|c|c|}
\hline Characteristics & Total sample & Women & Men \\
\hline All patients & $75983(100)$ & $13230(17.4)$ & $62753(82.6)$ \\
\hline \multicolumn{4}{|l|}{ Age (years): } \\
\hline $50-64$ & $14511(19.1)$ & $3073(23.2)$ & $11438(18.2)$ \\
\hline $65-79$ & $34194(45.0)$ & $4828(36.5)$ & $29366(46.8)$ \\
\hline$\geq 80$ & $27278(35.9)$ & $5329(40.3)$ & $21949(35.0)$ \\
\hline \multicolumn{4}{|l|}{ Type of urinary retention*: } \\
\hline Primary & $56439(74.3)$ & $7474(56.5)$ & $48965(78.0)$ \\
\hline Secondary & $19544(25.7)$ & $5756(43.5)$ & $13788(22.0)$ \\
\hline \multicolumn{4}{|l|}{ Type of hospital contact: } \\
\hline Inpatient & $33938(44.7)$ & $6008(45.4)$ & $27930(44.5)$ \\
\hline Outpatient & $25804(34.0)$ & $5912(44.7)$ & $19892(31.7)$ \\
\hline Emergency department & $16241(21.4)$ & $1310(9.9)$ & $14931(23.8)$ \\
\hline \multicolumn{4}{|l|}{ Comorbidities: } \\
\hline Urogenital disease & $36483(48.0)$ & $4733(35.8)$ & $31750(50.6)$ \\
\hline Neurological disease & $20774(27.3)$ & $4217(31.9)$ & $16557(26.4)$ \\
\hline Diabetes & $9996(13.2)$ & $1761(13.3)$ & $8235(13.1)$ \\
\hline \multicolumn{4}{|c|}{ Charlson comorbidity index score: } \\
\hline 0 & $34752(45.7)$ & $5844(44.2)$ & $28908(46.1)$ \\
\hline $1-2$ & $29105(38.3)$ & $5293(40.0)$ & $23812(38.0)$ \\
\hline$\geq 3$ & $12126(16.0)$ & $2093(15.8)$ & $10033(16.0)$ \\
\hline
\end{tabular}

to five years of follow-up, the risk of urinary tract cancer in men did not differ from that in the general population (standardised incidence ratio $1.1,1.0$ to 1.2). In women, the observed number of urinary tract cancers was 52 versus 28 expected during one to five

\begin{tabular}{|c|c|c|c|}
\hline \multirow[b]{2}{*}{ Characteristics } & \multicolumn{3}{|l|}{ Follow-up period } \\
\hline & 3 months & 1 year & 5 years \\
\hline Overall & 5.1 (4.9 to 5.3$)$ & 6.7 (6.6 to 6.9$)$ & 8.5 (8.3 to 8.7$)$ \\
\hline \multicolumn{4}{|l|}{ Age (years): } \\
\hline $50-64$ & 3.9 (3.6 to 4.3$)$ & $5.1(4.7$ to 5.5$)$ & $6.6(6.1$ to 7.0$)$ \\
\hline $65-79$ & $6.0(5.8$ to 6.3$)$ & 7.9 (7.6 to 8.2$)$ & $9.8(9.4$ to 10.1$)$ \\
\hline$\geq 80$ & $4.5(4.2$ to 4.7$)$ & $6.1(5.8$ to 6.4$)$ & $7.7(7.4$ to 8.1$)$ \\
\hline \multicolumn{4}{|l|}{ Calendar period: } \\
\hline 1995-98 & $5.7(5.2$ to 6.3$)$ & 7.5 (6.9 to 8.1$)$ & 9.1 (8.4 to 9.8$)$ \\
\hline 1999-2003 & $5.4(5.1$ to 5.9$)$ & $7.3(6.9$ to 7.8$)$ & $9.2(8.7$ to 9.7$)$ \\
\hline 2004-08 & $5.5(5.1$ to 5.8$)$ & $7.2(6.7$ to 7.6$)$ & 8.8 (8.3 to 9.3) \\
\hline $2009-13$ & $4.7(4.3$ to 5.0$)$ & $6.2(5.8$ to 6.6$)$ & $8.0(7.6$ to 8.4$)$ \\
\hline $2014-17$ & $4.6(4.2$ to 4.9$)$ & $6.0(5.6$ to 6.4$)$ & $7.7(7.1$ to 8.3$)$ \\
\hline \multicolumn{4}{|c|}{ Type of urinary retention*: } \\
\hline Primary & 5.0 (4.9 to 5.2$)$ & $6.8(6.6$ to 7.0$)$ & 8.7 (8.4 to 8.9$)$ \\
\hline Secondary & $5.3(4.9$ to 5.7$)$ & $6.6(6.2$ to 7.0$)$ & 7.9 (7.4 to 8.3$)$ \\
\hline \multicolumn{4}{|c|}{ Charlson comorbidity index score: } \\
\hline 0 & 6.8 (6.5 to 7.1$)$ & 8.8 (8.5 to 9.1$)$ & 11.0 (10.7 to 11.4$)$ \\
\hline $1-2$ & $4.2(4.0$ to 4.5$)$ & $5.8(5.5$ to 6.1$)$ & $7.2(6.9$ to 7.6$)$ \\
\hline$\geq 3$ & 2.3 (2.0 to 2.6$)$ & $3.2(2.9$ to 3.6$)$ & $4.0(3.7$ to 4.4$)$ \\
\hline \multicolumn{4}{|c|}{ Comorbidities } \\
\hline \multicolumn{4}{|c|}{ Urogenital disease: } \\
\hline No & $6.2(6.0$ to 6.5$)$ & $8.0(7.7$ to 8.3$)$ & 9.5 (9.2 to 9.9) \\
\hline Yes & $4.0(3.8$ to 4.2$)$ & $5.5(5.3$ to 5.8$)$ & $7.4(7.2$ to 7.7$)$ \\
\hline \multicolumn{4}{|c|}{ Neurological disease: } \\
\hline No & $5.9(5.7$ to 6.1$)$ & 7.7 (7.5 to 8.0$)$ & 9.6 (9.4 to 9.9) \\
\hline Yes & 2.9 (2.6 to 3.2$)$ & $4.0(3.7$ to 4.3$)$ & $5.2(4.9$ to 5.6$)$ \\
\hline \multicolumn{4}{|l|}{ Diabetes: } \\
\hline No & $5.4(5.2$ to 5.6$)$ & $7.1(6.9$ to 7.4$)$ & 8.9 (8.7 to 9.2) \\
\hline Yes & $3.1(2.7$ to 3.5$)$ & $4.2(3.7$ to 4.6$)$ & $5.4(5.0$ to 6.0$)$ \\
\hline
\end{tabular}

years of follow-up (standardised incidence ratio 1.9, 1.4 to 2.5). Invasive bladder cancer accounted for 29 of these cases (standardised incidence ratio 3.0, 95\% confidence interval 2.0 to 4.4 ).

Supplementary table 2 provides results from the subanalysis excluding patients with a diagnosis of concomitant haematuria. Although the risk estimates for the first three months of follow-up decreased after exclusion of patients with concomitant haematuria $(\mathrm{n}=3938,5.2 \%)$, the standardised incidence ratios for the first three months and during three to less than 12 months of follow-up remained increased for every urinary tract cancer investigated.

\section{Genital, colorectal, and neurological cancers}

Within three months after a first diagnosis of acute urinary retention in women, the observed number of genital cancers was 80 versus 5 expected, corresponding to 24 (95\% confidence interval 21 to 27) excess cases per 1000 person years (standardised incidence ratio $15.9,95 \%$ confidence interval 12.6 to 19.8). Of these, $37(46 \%)$ were ovarian cancers and 23 (29\%) were endometrial cancers. Prostate cancer accounted for most genital cancers in men within three months after a first diagnosis of acute urinary retention $(n=3198,99 \%)$.

Within three months of follow-up, the total number of observed colorectal cancers was 273 versus 63 expected (standardised incidence ratio 4.3, 95\% confidence interval 3.8 to 4.9). Of these, 244 were detected in men and 29 in women, corresponding to 13 and seven excess colorectal cancers per 1000 person years, respectively. Of these 273 cancers, 35\% were localised, $43 \%$ had spread locally or metastasised, and $19 \%$ had missing information on stage.

Within three months of follow-up, the number of observed neurological cancers was 46 versus 10 expected, corresponding to 2 (95\% confidence interval 2 to 2) excess neurological cancers per 1000 person years (standardised incidence ratio 4.7, 95\% confidence interval 3.4 to 6.2 ).

From three months and beyond no excess risk of genital cancers in women or colorectal and neurological cancers were detected. After three months of followup, absolute risks of genital cancers in women and colorectal and neurological cancers were low $(<1 \%$, table 4).

\section{Discussion}

In this population based cohort study, we found that a first diagnosis of acute urinary retention in patients aged 50 years or older was a clinical marker not only for prostate cancer but also for other urogenital cancers and colorectal and neurological cancers. The excess risk was particularly high for prostate and bladder cancer in men and bladder and genital cancer in women. For most cancers, the excess risk was confined to the first three months after a diagnosis of acute urinary retention. However, an excess risk of prostate cancer and urinary tract cancer persisted up to one year after the diagnosis of acute urinary retention. 
Table 3 | Excess risk and standardised incidence ratios of prostate cancer in 62753 men with a first diagnosis of acute urinary retention, stratified by patient characteristics

\begin{tabular}{|c|c|c|c|c|c|c|c|c|c|}
\hline \multirow[b]{3}{*}{ Characteristics } & \multicolumn{9}{|c|}{ Follow-up period } \\
\hline & \multicolumn{3}{|c|}{0 to $<3$ months } & \multicolumn{3}{|c|}{3 to $<12$ months } & \multicolumn{3}{|c|}{1 to 5 years } \\
\hline & O/E & $\begin{array}{l}\text { Excess risk per } \\
1000 \mathrm{PY}(95 \% \mathrm{Cl})\end{array}$ & SIR $(95 \% \mathrm{Cl})$ & O/E & $\begin{array}{l}\text { Excess risk per } \\
1000 \mathrm{PY} \\
(95 \% \mathrm{Cl})\end{array}$ & $\operatorname{SIR}(95 \% \mathrm{Cl})$ & O/E & $\begin{array}{l}\text { Excess risk } \\
\text { per } 1000 \mathrm{PY} \\
(95 \% \mathrm{Cl})\end{array}$ & $\operatorname{SIR}(95 \% \mathrm{CI})$ \\
\hline Overall & $3198 / 93$ & 218 (214 to 221$)$ & 34.5 (33.3 to 35.7 ) & $1035 / 244$ & 21 (20 to 23$)$ & $4.2(4.0$ to 4.5$)$ & $984 / 896$ & 1 (0 to 2$)$ & 1.1 (1.0 to 1.2$)$ \\
\hline \multicolumn{10}{|l|}{ Age (years): } \\
\hline $50-64$ & $448 / 6$ & $163(156$ to 170$)$ & $74.5(67.8$ to 81.8$)$ & $138 / 19$ & 16 (13 to 18$)$ & $7.4(6.2$ to 8.8$)$ & $149 / 113$ & $1(-1$ to 3$)$ & $1.3(1.1$ to 1.5$)$ \\
\hline $65-79$ & $1772 / 48$ & 256 (251 to 261$)$ & 37.0 (35.3 to 38.7$)$ & $544 / 132$ & $23(21$ to 25$)$ & 4.1 (3.8 to 4.5$)$ & $497 / 532$ & $-1(-2$ to 1$)$ & 0.9 (0.9 to 1.0$)$ \\
\hline$\geq 80$ & $978 / 39$ & 194 (189 to 200$)$ & $25.2(23.7$ to 26.9$)$ & $353 / 94$ & 22 (19 to 25$)$ & $3.8(3.4$ to 4.2$)$ & $338 / 251$ & $3(0$ to 5$)$ & $1.3(1.2$ to 1.5$)$ \\
\hline \multicolumn{10}{|l|}{ Calendar period: } \\
\hline $1995-98$ & $411 / 7$ & 249 (239 to 259$)$ & $57.3(51.9$ to 63.1$)$ & $128 / 19$ & $26(21$ to 31$)$ & $6.8(5.7$ to 8.1$)$ & $115 / 83$ & $2(-1$ to 5$)$ & $1.4(1.2$ to 1.7$)$ \\
\hline 1999-2003 & $664 / 16$ & $233(225$ to 240$)$ & $42.3(39.2$ to 45.7$)$ & $231 / 42$ & $26(22$ to 30$)$ & $5.5(4.8$ to 6.3$)$ & $226 / 190$ & $1(-1$ to 4$)$ & $1.2(1.0$ to 1.4$)$ \\
\hline $2004-08$ & $782 / 24$ & 234 (227 to 241$)$ & 31.9 (29.7 to 34.2$)$ & $245 / 64$ & 22 (18 to 25$)$ & $3.8(3.4$ to 4.3$)$ & $235 / 250$ & $0(-3$ to 2$)$ & $0.9(0.8$ to 1.1$)$ \\
\hline 2009-13 & $725 / 25$ & 197 (190 to 203) & $29.2(27.2$ to 31.5$)$ & $244 / 64$ & 19 (16 to 22$)$ & $3.8(3.3$ to 4.3$)$ & $279 / 254$ & 1 (-1 to 3$)$ & $1.1(1.0$ to 1.2$)$ \\
\hline $2014-17$ & $616 / 21$ & 194 (187 to 201) & $30.0(27.7$ to 32.4$)$ & $187 / 54$ & $16(13$ to 19$)$ & $3.4(3.0$ to 4.0$)$ & $129 / 119$ & $1(-2$ to 3$)$ & $1.1(0.9$ to 1.3$)$ \\
\hline \multicolumn{10}{|c|}{ Type of urinary retention*: } \\
\hline Primary & $2469 / 72$ & $212(208$ to 216$)$ & $34.2(32.8$ to 35.6$)$ & $856 / 193$ & $22(20$ to 24$)$ & $4.4(4.2$ to 4.8$)$ & $830 / 734$ & $1(-0$ to 2$)$ & 1.1 (1.1 to 1.2$)$ \\
\hline Secondary & $729 / 20$ & $239(232$ to 246$)$ & 35.6 (33.1 to 38.3 ) & $179 / 51$ & 17 (14 to 21$)$ & $3.5(3.0$ to 4.1$)$ & $154 / 162$ & $0(-3$ to 2$)$ & $0.9(0.8$ to 1.1$)$ \\
\hline \multicolumn{10}{|l|}{ Comorbidities } \\
\hline \multicolumn{10}{|c|}{ Urogenital disease } \\
\hline No & $1936 / 44$ & 273 (268 to 278$)$ & 44.1 (42.2 to 46.2$)$ & $545 / 114$ & $24(22$ to 26$)$ & $4.8(4.4$ to 5.2$)$ & $424 / 413$ & 0 (-1 to 2$)$ & $1.0(0.9$ to 1.1$)$ \\
\hline Yes & $1262 / 49$ & 165 (161 to 169$)$ & $25.8(24.4$ to 27.3$)$ & $490 / 130$ & $19(17$ to 21$)$ & $3.8(3.5$ to 4.1$)$ & $560 / 483$ & 1 ( -0 to 3$)$ & $1.2(1.1$ to 1.3$)$ \\
\hline \multicolumn{10}{|c|}{ Neurological disease } \\
\hline No & $2720 / 67$ & 253 (249 to 257$)$ & $40.8(39.3$ to 42.3$)$ & $856 / 177$ & $25(23$ to 26$)$ & $4.8(4.5$ to 5.2$)$ & $800 / 686$ & $1(-0$ to 2$)$ & $1.2(1.1$ to 1.3$)$ \\
\hline Yes & $478 / 26$ & 119 (114 to 124$)$ & 18.4 (16.8 to 20.1$)$ & $179 / 67$ & 11 (9 to 14$)$ & $2.7(2.3$ to 3.1$)$ & $184 / 211$ & $-1(-3$ to 1$)$ & $0.9(0.8$ to 1.0$)$ \\
\hline \multicolumn{10}{|l|}{ Diabetes } \\
\hline No & $2945 / 80$ & 231 (227 to 235) & 36.9 (35.6 to 38.2$)$ & $945 / 211$ & $23(21$ to 24$)$ & $4.5(4.2$ to 4.8$)$ & $890 / 792$ & $1(-0$ to 2$)$ & 1.1 (1.1 to 1.2$)$ \\
\hline Yes & $253 / 13$ & $128(120$ to 136$)$ & 19.7 (17.4 to 22.3$)$ & $90 / 33$ & $12(8$ to 16$)$ & $2.7(2.2$ to 3.4$)$ & $94 / 104$ & $-1(-4$ to 2$)$ & $0.9(0.7$ to 1.1$)$ \\
\hline \multicolumn{10}{|c|}{ Charlson comorbidity index score: } \\
\hline 0 & $1964 / 39$ & 292 (286 to 297$)$ & 49.9 (47.8 to 52.2$)$ & $578 / 108$ & 26 (24 to 29$)$ & $5.4(4.9$ to 5.8$)$ & $585 / 462$ & $2(0$ to 3$)$ & $1.3(1.2$ to 1.4$)$ \\
\hline $1-2$ & $1007 / 37$ & 179 (174 to 184$)$ & $27.0(25.4$ to 28.7$)$ & $363 / 97$ & 19 (17 to 22$)$ & 3.8 (3.4 to 4.2$)$ & $324 / 327$ & $0(-2$ to 2$)$ & $1.0(0.9$ to 1.1$)$ \\
\hline$\geq 3$ & $227 / 16$ & 93 (87 to 99$)$ & $14.1(12.3$ to 16.1$)$ & $94 / 39$ & $10(7$ to 13$)$ & $2.4(1.9$ to 2.9$)$ & $75 / 108$ & $-2(-5$ to 0$)$ & $0.7(0.5$ to 0.9$)$ \\
\hline
\end{tabular}

$\mathrm{O} / \mathrm{E}=$ observed/expected; $\mathrm{PY}=$ person years; $\mathrm{SIR}=$ standardised incidence ratio.

*Primary indicates acute urinary retention as a primary diagnosis or, in men, a diagnosis secondary to benign prostatic hyperplasia. All other cases were classified as secondary acute urinary retention.

\begin{tabular}{|c|c|c|c|}
\hline \multirow[b]{2}{*}{ Cancer site } & \multicolumn{3}{|l|}{ Follow-up period } \\
\hline & 3 months & 1 year & 5 years \\
\hline Urinary tract: & $1.3(1.3$ to 1.4$)$ & $1.8(1.7$ to 1.9$)$ & 2.5 (2.4 to 2.7$)$ \\
\hline Women & $0.9(0.7$ to 1.0$)$ & $1.1(0.9$ to 1.3$)$ & $1.5(1.3$ to 1.8$)$ \\
\hline Men & $1.5(1.4$ to 1.5$)$ & 2.0 (1.9 to 2.1$)$ & 2.8 (2.6 to 2.9$)$ \\
\hline Bladder (invasive cancer): & $0.6(0.5$ to 0.6$)$ & $0.8(0.7$ to 0.8$)$ & 1.1 (1.0 to 1.2$)$ \\
\hline Women & $0.5(0.4$ to 0.6$)$ & $0.6(0.5$ to 0.7$)$ & $0.8(0.7$ to 1.0$)$ \\
\hline Men & $0.6(0.5$ to 0.7$)$ & $0.8(0.7$ to 0.9$)$ & $1.2(1.1$ to 1.2$)$ \\
\hline Bladder (non-invasive cancer): & $0.5(0.5$ to 0.6$)$ & 0.7 (0.7 to 0.8$)$ & 0.9 (0.9 to 1.0$)$ \\
\hline Women & $0.2(0.2$ to 0.3$)$ & $0.3(0.2$ to 0.4$)$ & $0.3(0.3$ to 0.5$)$ \\
\hline Men & $0.6(0.6$ to 0.7$)$ & $0.8(0.7$ to 0.9$)$ & $1.0(1.0$ to 1.1$)$ \\
\hline Kidney: & $0.2(0.1$ to 0.2$)$ & $0.2(0.2$ to 0.3$)$ & $0.4(0.4$ to 0.5$)$ \\
\hline Women & $0.1(0.1$ to 0.2$)$ & $0.2(0.1$ to 0.2$)$ & $0.3(0.2$ to 0.4$)$ \\
\hline Men & $0.2(0.2$ to 0.2$)$ & $0.3(0.2$ to 0.3$)$ & $0.4(0.4$ to 0.5$)$ \\
\hline Renal pelvis: & $0.0(0.0$ to 0.0$)$ & $0.0(0.0$ to 0.1$)$ & $0.1(0.0$ to 0.1$)$ \\
\hline Women & $0.0(0.0$ to 0.1$)$ & $0.0(0.0$ to 0.1$)$ & $0.0(0.0$ to 0.1$)$ \\
\hline Men & $0.0(0.0$ to 0.0$)$ & $0.0(0.0$ to 0.1$)$ & 0.1 (0.0 to 0.1) \\
\hline \multicolumn{4}{|l|}{ Genitals: } \\
\hline Women & $0.6(0.5$ to 0.8$)$ & 0.8 (0.6 to 0.9$)$ & $1.1(1.0$ to 1.3$)$ \\
\hline Men & $5.2(5.0$ to 5.3$)$ & $6.9(6.7$ to 7.1$)$ & $8.7(8.5$ to 8.9$)$ \\
\hline Colorectum: & $0.4(0.3$ to 0.4$)$ & $0.6(0.6$ to 0.7$)$ & $1.5(1.4$ to 1.6$)$ \\
\hline Women & $0.2(0.2$ to 0.3$)$ & $0.5(0.4$ to 0.6$)$ & $1.1(0.9$ to 1.3$)$ \\
\hline Men & $0.4(0.4$ to 0.5$)$ & $0.6(0.6$ to 0.7$)$ & $1.6(1.5$ to 1.7$)$ \\
\hline Nervous system: & $0.1(0.0$ to 0.1$)$ & $0.1(0.1$ to 0.1$)$ & $0.3(0.2$ to 0.3$)$ \\
\hline Women & $0.1(0.0$ to 0.2$)$ & $0.1(0.1$ to 0.2$)$ & $0.3(0.2$ to 0.4$)$ \\
\hline Men & $0.1(0.0$ to 0.1$)$ & $0.1(0.1$ to 0.1$)$ & $0.3(0.2$ to 0.3$)$ \\
\hline
\end{tabular}

\section{Strengths and weaknesses of this study}

We used data from the Danish health registries, which are prospectively collected and have virtually complete follow-up. ${ }^{19}$ Owing to the completeness of the Danish Cancer Registry, ${ }^{14}$ we expect to have captured virtually all cancer diagnoses. The data quality of the registries used in our study is generally high ${ }^{13}{ }^{14}$; the positive predictive value of acute urinary retention in men in the Danish National Patient Registry is 98\% (95\% confidence interval $93 \%$ to $99 \%) .^{20}$ Although the diagnosis of acute urinary retention has not been validated specifically in women, we also expected a high positive predictive value among women. A concern is that we might not have captured all patients admitted to hospital with acute urinary retention, as those with an obvious underlying cause might have received a diagnosis code only for that condition. Our cohort is, however, likely to be complete for patients with no obvious cause of acute urinary retention after initial investigations. Also, we included only patients with a hospital (inpatient, outpatient, or emergency department) diagnosis. Although current guidelines recommend referral to a specialist for all patients presenting with acute urinary retention and residual urine $>100 \mathrm{~mL},{ }^{21}$ general practitioners might have treated patients with an obvious benign underlying 


\begin{tabular}{|c|c|c|c|c|c|c|c|c|c|}
\hline \multirow[b]{3}{*}{ Cancer site } & \multicolumn{9}{|c|}{ Follow-up period } \\
\hline & \multicolumn{3}{|c|}{0 to $<3$ months } & \multicolumn{3}{|c|}{3 to $<12$ months } & \multicolumn{3}{|l|}{1 to 5 years } \\
\hline & O/E & $\begin{array}{l}\text { Excess risk } \\
\text { per } 1000 \mathrm{PY} \\
(95 \% \mathrm{Cl})\end{array}$ & SIR $(95 \% \mathrm{CI})$ & O/E & $\begin{array}{l}\text { Excess risk } \\
\text { per } 1000 \mathrm{PY} \\
(95 \% \mathrm{Cl})\end{array}$ & SIR $(95 \% \mathrm{CI})$ & $0 / E$ & $\begin{array}{l}\text { Excess risk } \\
\text { per } 1000 \mathrm{PY} \\
(95 \% \mathrm{Cl})\end{array}$ & $\operatorname{SIR}(95 \% \mathrm{Cl})$ \\
\hline Urinary tract: & $1025 / 49$ & 56 (54 to 58$)$ & 21.1 (19.9 to 22.5$)$ & $354 / 127$ & $5(4$ to 6$)$ & 2.8 (2.5 to 3.1$)$ & $497 / 454$ & $0(0$ to 1$)$ & 1.1 (1.0 to 1.2$)$ \\
\hline Women & $114 / 3$ & 36 (32 to 39 ) & 40.5 (33.4 to 48.7$)$ & $32 / 8$ & $3(2$ to 4$)$ & $4.2(2.9$ to 5.9$)$ & $52 / 28$ & 1 (0 to 2 ) & $1.9(1.4$ to 2.5$)$ \\
\hline Men & $911 / 46$ & 61 (59 to 63 ) & 19.9 (18.7 to 21.3) & $322 / 119$ & $5(5$ to 6$)$ & 2.7 (2.4 to 3.0$)$ & $445 / 426$ & $0(-1$ to 1$)$ & 1.0 (1.0 to 1.2$)$ \\
\hline $\begin{array}{l}\text { Bladder (invasive } \\
\text { cancer): }\end{array}$ & $434 / 20$ & $24(23$ to 25$)$ & 22.2 (20.1 to 24.3 ) & $149 / 51$ & 2 (2 to 3$)$ & $2.9(2.5$ to 3.4$)$ & $228 / 181$ & 0 (0 to 1) & 1.3 (1.1 to 1.4$)$ \\
\hline Women & $62 / 1$ & $20(17$ to 22$)$ & $63.2(48.5$ to 81.1$)$ & $14 / 3$ & 1 (1 to 2$)$ & $5.3(2.9$ to 8.9$)$ & $29 / 10$ & 1 (0 to 1$)$ & $3.0(2.0$ to 4.4$)$ \\
\hline Men & $372 / 19$ & 25 (23 to 26$)$ & 20.0 (18.0 to 22.1$)$ & $135 / 48$ & $2(2$ to 3$)$ & $2.8(2.4$ to 3.3$)$ & $199 / 171$ & $0(0$ to 1$)$ & $1.2(1.0$ to 1.3$)$ \\
\hline $\begin{array}{l}\text { Bladder (non- } \\
\text { invasive cancer): }\end{array}$ & $413 / 18$ & $23(22$ to 24$)$ & 22.4 (20.3 to 24.7$)$ & $129 / 48$ & 2 (1 to 2$)$ & 2.7 (2.2 to 3.2$)$ & $140 / 172$ & $0(-1$ to 0$)$ & 0.8 (0.7 to 1.0$)$ \\
\hline Women & $30 / 1$ & 9 (8 to 11$)$ & 38.3 (25.8 to 54.7$)$ & $10 / 2$ & 1 (0 to 2$)$ & $4.7(2.2$ to 8.6$)$ & $5 / 8$ & $0(0$ to 0$)$ & 0.6 (0.2 to 1.5$)$ \\
\hline Men & $383 / 18$ & 26 (24 to 27$)$ & 21.7 (19.6 to 24.0$)$ & $119 / 46$ & 2 (1 to 3$)$ & $2.6(2.2$ to 3.1$)$ & $135 / 164$ & $0(-1$ to 0$)$ & 0.8 (0.7 to 1.0$)$ \\
\hline Kidney: & $130 / 8$ & 7 (6 to 8$)$ & 16.3 (13.6 to 19.4$)$ & $57 / 21$ & 1 (0 to 1$)$ & 2.7 (2.0 to 3.5$)$ & $108 / 77$ & $0(0$ to 0$)$ & $1.4(1.2$ to 1.7$)$ \\
\hline Women & $15 / 1$ & $5(3$ to 6$)$ & 19.2 (10.7 to 31.7$)$ & $6 / 2$ & 0 (0 to 1$)$ & 2.8 (1.0 to 6.1$)$ & $13 / 8$ & 0 (0 to 1) & 1.7 (0.9 to 2.9$)$ \\
\hline Men & $115 / 7$ & 8 (7 to 8$)$ & 16.0 (13.2 to 19.2$)$ & $51 / 19$ & $1(0$ to 1$)$ & 2.7 (2.0 to 3.5) & $95 / 69$ & $0(0$ to 1$)$ & 1.4 (1.1 to 1.7$)$ \\
\hline Renal pelvis* & $23 / 1$ & 1 (1 to 2$)$ & 17.2 (10.9 to 25.9$)$ & $12 / 3$ & $0(0$ to 0$)$ & 3.5 (1.8 to 6.1$)$ & $7 / 12$ & $0(0$ to 0$)$ & $0.6(0.2$ to 1.2$)$ \\
\hline \multicolumn{10}{|l|}{ Genitals: } \\
\hline Women & $80 / 5$ & $24(21$ to 27$)$ & 15.9 (12.6 to 19.8$)$ & $19 / 14$ & $1(0$ to 2$)$ & $1.4(0.8$ to 2.2$)$ & $42 / 50$ & $0(-1$ to 1$)$ & 0.8 (0.6 to 1.1$)$ \\
\hline Men & $3216 / 94$ & 219 (215 to 222$)$ & 34.0 (32.9 to 35.2 ) & $1039 / 248$ & 21 (20 to 23) & $4.2(3.9$ to 4.5$)$ & $1005 / 913$ & 1 (0 to 2$)$ & 1.1 (1.0 to 1.2$)$ \\
\hline Colorectum: & $273 / 63$ & 12 (11 to 13$)$ & $4.3(3.8$ to 4.9$)$ & $170 / 165$ & $0(-1$ to 1$)$ & $1.0(0.9$ to 1.2$)$ & $532 / 594$ & $0(-1$ to 0$)$ & 0.9 (0.8 to 1.0$)$ \\
\hline Women & $29 / 8$ & $7(5$ to 9$)$ & 3.5 (2.4 to 5.1$)$ & $32 / 22$ & 1 (0 to 3$)$ & 1.4 (1.0 to 2.0$)$ & $72 / 80$ & $0(-2$ to 1$)$ & $0.9(0.7$ to 1.1$)$ \\
\hline Men & $244 / 55$ & $13(12$ to 14$)$ & 4.5 (3.9 to 5.1$)$ & $138 / 143$ & $0(-1$ to 1$)$ & $1.0(0.8$ to 1.1$)$ & $460 / 514$ & $0(-1$ to 0$)$ & 0.9 (0.8 to 1.0$)$ \\
\hline Nervous system: & $46 / 10$ & $2(2$ to 2$)$ & 4.7 (3.4 to 6.2$)$ & $29 / 26$ & $0(0$ to 0$)$ & $1.1(0.7$ to 1.6$)$ & $114 / 97$ & $0(0$ to 0$)$ & $1.2(1.0$ to 1.4$)$ \\
\hline Women & $11 / 2$ & $3(2$ to 4$)$ & $6.2(3.1$ to 11.2$)$ & $7 / 5$ & 0 (0 to 1$)$ & $1.4(0.6$ to 2.9$)$ & $19 / 18$ & $0(-1$ to 1$)$ & 1.0 (0.6 to 1.6$)$ \\
\hline Men & $35 / 8$ & 2 (1 to 2$)$ & $4.3(3.0$ to 6.0$)$ & $22 / 21$ & 0 (0 to 0$)$ & $1.0(0.6$ to 1.6$)$ & $95 / 79$ & $0(0$ to 0$)$ & $1.2(1.0$ to 1.5$)$ \\
\hline
\end{tabular}

$\mathrm{O} / \mathrm{E}=$ observed/expected; $\mathrm{PY}=$ person years; $\mathrm{SIR}=$ standardised incidence ratio.

*Numbers were too few to separate by sex.

cause without hospital referral. Consequently, patients treated by general practitioners might have a lower risk of cancer than patients with a hospital referral. Patients with acute urinary retention are in closer contact with the hospital system than people in the general population, therefore increased diagnostic attention could potentially explain at least some of the excess risk of cancer diagnoses. The short term increased risk of colorectal cancer is thus probably explained by enhanced diagnostic investigations (for example, digital rectal examination and detection of anaemia). If the increase exclusively occurred as a result of more intense medical attention though, we would expect a compensatory decrease in cancer occurrence after this increase. The one to five year standardised incidence ratios did not support such a compensatory decrease. However, if some of the patients with acute urinary retention were not evaluated by a cancer specialist during follow-up, we might have missed some cancers. Still, missed cancers also occur in the general population and we therefore expect such potential bias to be negligible.

The incidence ratios in our study were standardised for sex, age, and calendar time but did not take into account differences in lifestyle factors or comorbidities. For the cancers that occurred shortly after the diagnosis of acute urinary retention, however, we expect reverse causation and adjustment for shared risk factors would therefore not be relevant. For the cancers that occurred later during follow-up, lifestyle factors could be potential confounders, although our finding of a lack of any substantial increase in excess cancer risk disproves the presence of substantial residual confounding. Also, a US study from Olmsted County in Minnesota found that men who were current smokers had a slightly reduced risk of acute urinary retention (relative risk $0.78,95 \%$ confidence interval 0.41 to 1.49 ) compared with non-smokers. ${ }^{22}$ Thus patients with acute urinary retention are not expected to have higher rates of smoking compared with the general population. In addition, we analysed data categorising the acute urinary retention cohort according to whether or not comorbidities were recorded and we observed an excess risk of cancer among patients without comorbidities who would likely have a lower prevalence of smoking and other adverse lifestyle factors compared with patients with recorded comorbidities. As Denmark is a homogeneous country with low racial diversity, confounding by race or ethnicity is expected to be negligible.

\section{Comparison with other literature}

Limited evidence exists on the risk of cancer after acute urinary retention. Although several case reports have suggested that acute urinary retention can be the presenting sign of cancers other than prostate cancer, ${ }^{23-30}$ no study has quantified this association. One study carried out at a hospital in the UK during 1979-80-before the era of prostate specific antigenprovided some evidence on the risk of cancer after acute urinary retention. The authors reported a $7 \%$ risk of prostate cancer after initial diagnostic 
investigations in 310 men, which agrees with our finding of $5.1 \%$ at three months after a diagnosis of acute urinary retention. We found that an excess risk of prostate cancer persisted during the first year of follow-up. Thereafter the risk did not differ from that in the general population. In Denmark during the study period only individual based screening for prostate specific antigen initiated by the patient or doctor for case specific reasons existed. Since 2004 the Danish guidelines have recommended prostate specific antigen testing in men presenting with lower urinary tract symptoms. Implementation of prostate specific antigen testing in men with lower urinary tract symptoms has been shown to result in a rapid increase in the incidence of prostate cancer. ${ }^{31}$ Nevertheless, our data indicated that the risk of prostate cancer after a first diagnosis of acute urinary retention decreased slightly over calendar time. If prostate cancer is increasingly being detected because of systematic testing for prostate specific antigen as part of the diagnostic investigations for lower urinary tract symptoms rather than for acute urinary retention, this might explain the decreasing risk of prostate cancer after a first diagnosis of acute urinary retention over calendar time. The risk of prostate cancer was highest in men without previous comorbidities. This suggests that acute urinary retention in men with comorbidities could be more often explained by causes other than cancer, whereas acute urinary retention occurring in men without previous comorbidities is more likely to be a marker of underlying prostate cancer.

A study from England reported a high mortality in men admitted to hospital with acute urinary retention. ${ }^{16}$ Even in men without previous comorbidities, mortality was 1.6-2.3 times higher than that observed in men of similar age in the general population. Our findings suggest that occult cancer might partly explain the high mortality observed in men admitted to hospital with acute urinary retention. Whether acute urinary retention also results in a high mortality in women remains to be elucidated. Nevertheless, our data indicate that occult cancer should be considered in women presenting with acute urinary retention as well. An excess risk of bladder cancer in women persisted for several years. Malignant transformation of benign tumours of the bladder might partly explain this sustained increased risk of bladder cancer in women; in men, however, the excess risk did not persist after the first year of follow-up. This sustained increased risk of urinary tract cancers in women merits attention, as it might represent an opportunity for earlier diagnosis of these cancers.

\section{Implications, future research, and conclusions}

In this population based cohort study, a first diagnosis of acute urinary retention was a clinical marker for occult cancer. We found that not only prostate cancer but also other urogenital, colorectal, and neurological cancers should be considered in patients aged 50 years or older who present with acute urinary retention and no obvious underlying cause. For most cancers, no excess risk was observed beyond three months of follow-up, suggesting that no major delay in cancer detection occurred. Whether the sustained increased risk of prostate and urinary tract cancers persisting for more than three months of follow-up represents an opportunity for earlier detection of these cancers remains to be elucidated and could be a focus for future research.

Contributors: MBB, DKF, HTS, and MN designed and planned the study. MBB performed the literature search. HTS acquired the data. DKF performed the statistical analysis. MBB was responsible for the initial draft of the manuscript and all authors were involved in interpreting the results, revising the manuscript, and approving the final version. HTS is the guarantor. HTS and DKF had full access to all the data in the study and take responsibility for the integrity of the data and the accuracy of the data analysis. The corresponding author attests that all listed authors meet authorship criteria and that no others meeting the criteria have been omitted.

Funding: None.

Competing interests: All authors have completed the ICMJE uniform disclosure form at www.icmje.org/disclosure-of-interest/. and declare: no support from any organisation for the submitted work; no financial relationships with any organisations that might have an interest in the submitted work in the previous three years; no other relationships or activities that could appear to have influenced the submitted work.

Ethical approval: Not required. This study was reported to the Danish Data Protection Agency through registration at Aarhus University (record No KEA-2017-36/812).

Data sharing: The datasets analysed during the current study are not freely available owing to national regulations, but similar data are accessible to authorised researchers after application to the Danish Health Data Authority.

The corresponding author (MBB) affirms that the manuscript is an honest, accurate, and transparent account of the study being report; that no important aspects of the study have been omitted; and that any discrepancies from the study as planned and registered have been explained.

Dissemination to participants and related patient and public communities: Dissemination of the results to the study participants is not possible. We plan to disseminate the results of the research to the general public, mainly through media outreach (eg, press releases by the research institutions of the contributing authors)

Provenance and peer review: Not commissioned; externally peer reviewed.

This is an Open Access article distributed in accordance with the Creative Commons Attribution Non Commercial (CC BY-NC 4.0) license, which permits others to distribute, remix, adapt, build upon this work non-commercially, and license their derivative works on different terms, provided the original work is properly cited and the use is noncommercial. See: http://creativecommons.org/licenses/by-nc/4.0/.

Thomas K, Chow K, Kirby RS. Acute urinary retention: a review of the aetiology and management. Prostate Cancer Prostatic Dis 2004;7:32-7. doi:10.1038/sj.pcan.4500700

2 Thorne MB, Geraci SA. Acute urinary retention in elderly men. Am J Med 2009;122:815-9. doi:10.1016/j.amjmed.2009.05.009

3 Oelke M, Speakman MJ, Desgrandchamps F, Mamoulakis C. Acute Urinary Retention Rates in the General Male Population and in Adult Men With Lower Urinary Tract Symptoms Participating in Pharmacotherapy Trials: A Literature Review. Urology 2015;86:65465. doi:10.1016/j.urology.2015.06.025

4 Jacobsen SJ, Jacobson DJ, Girman C), et al. Natural history of prostatism: risk factors for acute urinary retention. J Urol 1997;158:481-7. doi:10.1016/S0022-5347(01)64508-7

5 Klarskov P, Andersen JT, Asmussen CF, et al. Acute urinary retention in women: a prospective study of 18 consecutive cases. Scand J Urol Nephrol 1987;21:29-31. doi:10.3109/00365598709180286

6 Selius BA, Subedi R. Urinary retention in adults: diagnosis and initial management. Am Fam Physician 2008;77:643-50.

7 Billet M, Windsor TA. Urinary Retention. Emerg Med Clin North Am 2019;37:649-60. doi:10.1016/j.emc.2019.07.005

8 Choong S, Emberton M. Acute urinary retention. BJU Int 2000;85:186-201. doi:10.1046/j.1464-410x.2000.00409.x

9 Murray K, Massey A, Feneley RC. Acute urinary retention--a urodynamic assessment. Br J Urol 1984;56:468-73. 
10 Statistics Denmark. Population in Denmark. https://www.dst. dk/da/Statistik/emner/befolkning-og-valg/befolkning-ogbefolkningsfremskrivning/folketal

11 Frank L. Epidemiology. When an entire country is a cohort. Science 2000;287:2398-9. doi:10.1126/science.287.5462.2398

12 Schmidt M, Pedersen L, Sørensen HT. The Danish Civil Registration System as a tool in epidemiology. Eur J Epidemiol 2014;29:541-9. doi:10.1007/s10654-014-9930-3

13 Schmidt M, Schmidt SA, Sandegaard IL, Ehrenstein V, Pedersen L, Sørensen HT. The Danish National Patient Registry: a review of content, data quality, and research potential. Clin Epidemiol 2015:7:449-90 doi:10.2147/CLEPS91125

14 Storm HH, Michelsen EV, Clemmensen IH, Pihl J. The Danish Cancer Registry--history, content, quality and use. Dan Med Bull 1997;44:535-9.

15 Charlson ME, Pompei P, Ales KL, MacKenzie CR. A new method of classifying prognostic comorbidity in longitudinal studies: development and validation. J Chronic Dis 1987;40:373-83. doi:10.1016/0021-9681(87)90171-8

16 Armitage JN, Sibanda N, Cathcart PJ, Emberton M, van der Meulen JHP. Mortality in men admitted to hospital with acute urinary retention: database analysis. BMJ 2007;335:1199-202. doi:10.1136/ bmj.39377.617269.55

17 Cathcart P, van der Meulen J, Armitage J, Emberton M. Incidence of primary and recurrent acute urinary retention between 1998 and 2003 in England. / Urol 2006;176:200-4, discussion 204 doi:10.1016/S0022-5347(06)00509-X

18 Satagopan JM, Ben-Porat L, Berwick M, Robson M, Kutler D, Auerbach AD. A note on competing risks in survival data analysis. $\mathrm{Br}$ Cancer 2004;91:1229-35. doi:10.1038/sj.bjc.6602102

19 Schmidt M, Schmidt SAJ, Sandegaard JL, Ehrenstein V, Pedersen L, Sørensen HT. The Danish National Patient Registry: a review of content, data quality, and research potential. Clin Epidemiol 2015;7:449-90. doi:10.2147/CLEP.S91125

20 Bengtsen MB, Heide-Jørgensen U, Blichert-Refsgaard LS, Hjelholt TJ, Borre M, Nørgaard M. Positive predictive value of benign prostatic hyperplasia and acute urinary retention in the danish national patient registry: A validation study. Clin Epidemiol 2020;12:1281-5. doi:10.2147/CLEP.S278554

21 The Danish College of General Practitioners. Udredning Og Behandling Af Nedre Urinvejssymptomer Hos Mænd Og Kvinder Klinisk Vejledning for Almen Praksis. The Danish College of General Practitioners, 2009.
22 Sarma AV, Jacobson DJ, St Sauver JL, et al. Smoking and acute urinary retention: the Olmsted County study of urinary symptoms and health status among men. Prostate 2009;69:699-705. doi:10.1002/ pros. 20914

23 Lang EW, Chesnut RM, Hennerici M. Urinary retention and spaceoccupying lesions of the frontal cortex. Eur Neurol 1996;36:43-7. doi:10.1159/000117199

24 Martingano D, Ramírez LC, Bjurlin MA. Osteopathic evaluation of urinary retention caused by atypical presentation of invasive cervical cancer mimicking primary urothelial tumor. J Am Osteopath Assoc 2018;118:685-8. doi:10.7556/jaoa.2018.148

25 Mihai I, Taban S, Cumpanas A, Olteanu EG, Iacob M, Dema A. Clear cell urothelial carcinoma of the urinary bladder - a rare pathological entity. A case report and a systematic review of the literature. Bosn J Basic Med Sci 2019;19:400-3. doi:10.17305/bjbms.2019.4182

26 Oluyadi F, Ramachandran P, Gotlieb V. A Rare Case of Advanced Urethral Diverticular Adenocarcinoma and a Review of Treatment Modalities. J Investig Med High Impact Case Rep 2019;7:2324709619828408. doi:10.1177/2324709619828408

27 Singh S, Jena SK, Naik M, Ray L, Behera S. Uterine fibroid (leiomyoma) with acute urinary retention: A case series. J Clin Diagn Res 2016:10:QR01-03. doi:10.7860/JCDR/2016/17028.7573

28 Sountoulides P, Bantis A, Zachos I, Asouhidou I, Pantazakos A. "Vanishing penis" and urinary retention due to locally destructive penile cancer. ScientificWorldJournal 2009;9:158-62. doi:10.1100/ tsw.2009.14

29 Takizawa H, Abe K, Ueki T. A case of small cell carcinoma in a diverticulum of the bladder. Nihon Hinyokika Gakkai Zasshi 2019;110:261-5. doi:10.5980/jpnjurol.110.261

30 Wu CQ, Lefebvre G, Frecker H, Husslein H. Urinary retention and uterine leiomyomas: a case series and systematic review of the literature. Int Urogynecol / 2015;26:1277-84. doi:10.1007/s00192015-2665-1

31 Bray F, Lortet-Tieulent J, Ferlay J, Forman D, Auvinen A. Prostate cancer incidence and mortality trends in 37 European countries: an overview. Eur J Cancer 2010;46:3040-52. doi:10.1016/j. ejca.2010.09.013

Supplementary information: tables showing ICD codes used in the study and results of subanalysis excluding patients with haematuria 